\title{
Correction of Caudal Septal Deviation: Septal Batten Graft with a Bioabsorbable Plate
}

\author{
Bo Sung Kang, Jeong Tae Kim, Hyun Soo Lee, and Jae-Min Shin \\ Department of Otolaryngology-Head and Neck Surgery, Soonchunhyang University College of Medicine, Seoul, Korea
}

\section{생체흡수성 판 부목이식을 이용한 비중격 미부 만곡증의 교정}

강보성 · 김정태 · 이현수 · 신재민

순천향대학교 의과대학 이비인후과학교실

\author{
Received September 11, 2015 \\ Revised December 24, 2015 \\ Accepted December 30, 2015 \\ Address for correspondence \\ Jae-Min Shin, MD \\ Department of Otolaryngology- \\ Head and Neck Surgery, \\ Soonchunhyang University \\ College of Medicine, \\ 59 Daesagwan-ro, Yongsan-gu, \\ Seoul 04401, Korea \\ Tel $+82-2-709-9360$ \\ Fax $+82-2-709-9134$ \\ E-mail jmshin95@naver.com
}

Caudal septal deviation is difficult to correct due to elasticity of cartilage. Septal batten graft is a useful surgical technique used for correction of caudal septal deviation and the septal cartilage is used mainly for graft material. However, in some cases (i.e., revision surgery), its quality may be insufficient or inadequate to be useful. Septal batten graft with a bioabsorbable plate can be an alternative in these cases. The use of a bioabsorbable plate connected with septal cartilage would facilitate surgical correction of severe caudal septal deviation and offer mechanical stability until the manipulated cartilage heals. With a brief review of the literature, we describe our experience of treating a 29 -year-old woman with severe caudal septal deviation and clinical summary of 7 patients who underwent septal batten graft using a bioabsorbable plate for caudal septal deviation.

Korean J Otorhinolaryngol-Head Neck Surg 2016;59(9):680-3

Key Words Alloplastic · Batten graft · Bioabsorbable plate - Caudal septal deviation . Septoplasty.

\section{서 론}

비중격기형(septal deformity)을 교정하기 위한 비중격교 정술(septoplasty)은 이비인후과에서 가장 흔하게 시행하는 수술 중의 하나이다. 하지만 사람마다 비중격기형의 형태와 정도가 다양하기 때문에 단일술식만으로는 항상 일정하고 만족스러운 결과를 기대하기 힘들다. ${ }^{1)}$ 특히 비중격 미부(caudal septum)는 외비 구조를 유지시켜주는 L형 지주(L-shaped strut)가 포함되어 있기 때문에, 이 부위의 만곡이 심한 경우 중 앙부위 비중격과 달리 절제를 통한 교정이 어렵고, 교차절개 (crosshatching incision), 쐐기모양 절제(wedge shape resection)와 같은 고식적인 방법으로는 만곡이 불충분하게 교정 되거나 과도하게 교정되는 사례가 빈번하여 일정한 수술 결과 를 기대하기도 힘들다. ${ }^{2}$ 특히 만곡을 교정하는 목적으로 비중 격 미부의 과도한 절개를 가한 경우 지지구조의 약화로 이차
적인 외비기형의 발생도 흔히 보고되고 있어 한계가 있다. ${ }^{3)}$

최근에는 이런 단점을 보완한 술식으로 부목이식(batten graft)을 이용한 비중격 미부 교정법에 대한 연구가 많이 소개 되고 있으며, 만족스러운 임상 결과들을 보고하고 있다.) 일반 적으로 부목이식의 재료는 수술 중에 얻어지는 비중격 연골 을 주로 사용하지만, ${ }^{5,6)}$ 해부학적 기형을 교정하기에 충분한 크기와 강도를 가진 반듯한 자가조직을 얻을 수 없는 경우에 는 제한되며, 동일 수술부위가 아닌 다른 부위에서 이식편을 채취하는 경우 공여부의 통증, 염증과 같은 공여부 이환의 문 제가 있다.

저자들은 비중격 미부의 만곡이 있는 환자 7명을 대상으로 생체흡수성 판(bioabsorbable plate)을 이용하여 부목이식을 시행하였고, 경과 관찰 기간 동안 비중격 기형의 재발 없이 잘 유지되어, 이중 비중격 미부 만곡증을 비내접근법으로 치료한 1 예를 소개하고 같은 재료를 사용하여 수술한 7 명의 환자들 
의 현재까지의 임상 경과를 문헌과 함께 보고하고자 한다.

\section{증 례}

\section{Case 1}

29세 여자 환자가 5년 전 외상 이후 발생한 좌측 코막힘을 주 소로 내원하였다. 외래에서 시행한 전비경 및 비내시경에서 좌측 비공을 거의 폐쇄하고 있는 심한 비중격 미부 만곡이 관 찰되었다(Fig. 1A). 비내접근법으로 비중격 연골을 이용한 부 목이식을 통한 비중격 미부 만곡을 교정할 계획으로 수술을 시행하였다. 우측 비중격 미부의 끝에서 약 $2 \mathrm{~mm}$ 후방에 반관 통절개(hemitransfixion incision)를 가하여 전비극과 이상구 를 향하여 절개를 연장하였다. 절개부위에서 Freer 거상기를 이용하여 점막연골막을 조심스럽게 박리하자 비중격 연골 미 부에 배측에서 복측 방향으로 가로지르는 골절선을 동반한 각형성(angulation) 부위가 관찰되었다(Fig. 2A). 거상기를 이 용하여 후방의 점막판을 박리한 이후 반대편 비중격 미부 연 골의 점막연골막을 박리하여 비중격 연골 미부를 완전히 노 출시켰다.

비중격 연골의 골절 부위와 비중격 골(septal bone) 형태와 두께를 고려했을 때 부목이식에 필요한 충분한 크기와 강도 의 자가조직 이식편를 확보하기 어렵다고 판단하였다. 골절선 후방의 만곡은 Freer septal knife를 이용하여 연골의 하단부 를 상악릉(maxillary crest)에서 분리한 이후 잉여연골(excess cartilage)을 제거하여 교정하였고, 전방부위의 만곡은 각형성 이 유발된 골절선을 따라 Freer septal knife를 이용하여 잉여 연골을 절제하여 만곡을 교정하였다. 하지만 L형 지주 배측부 의 일부가 연골 절제범위에 포함되었고, 이로 인한 수술 후 L 형 지주의 지지력 약화가 예상되었다.

수술 이후 재만곡을 방지하고 미중격 미부의 지지력을 보 강하기 위해 $0.3 \mathrm{~mm}$ 두께의 생체흡수성 판(Resorb-X ${ }^{\circledR}$; KLS Martin, Tuttlingen, Germany)을 비중격 미부 연골크기에 맞게 재단하고 연골의 우측(오목면)에 위치시켰다(Fig. 2B and C). 생체흡수성 판과 연골을 24게이지 바늘침으로 움직이 지 않도록 고정시킨 후 5-0 PDS ${ }^{\circledR}$ (Ethicon, Johnson \& Johnson, Cincinnati, $\mathrm{OH}, \mathrm{USA}$ )로 연골과 함께 봉합을 시행하여 비중격 미부의 만곡을 완전히 교정함과 동시에 약화된 L형 지 주를 보강하였다(Fig. 2D). 반관통절개부위를 5-0 Vicryl ${ }^{\circledR}$ (Ethicon, Johnson \& Johnson)을 이용하여 봉합한 이후 비중 격을 실라스틱부목(silastic splint)으로 고정하였고, 동반된 양 측 하비갑개의 비후는 회전식흡입기 하비갑개 수술(microdebrider-assisted inferior turbinoplasty)법을 이용하여 교정 하였다. 수술 부위에 출혈이 없음을 확인한 뒤 패킹을 하고 수 술을 종료하였다. 수술로 비중격 미부의 만곡증은 잘 교정되 었고(Fig. $1 \mathrm{~B})$, 이후 9개월의 추적 관찰 기간 동안 비중격 혈 종이나 감염, 만곡의 재발, 안장코, 코길이의 짧아짐 등의 구조 적인 합병증은 관찰되지 않았으며, 코막힘 증상의 주관적 개 선도 지속되었다.
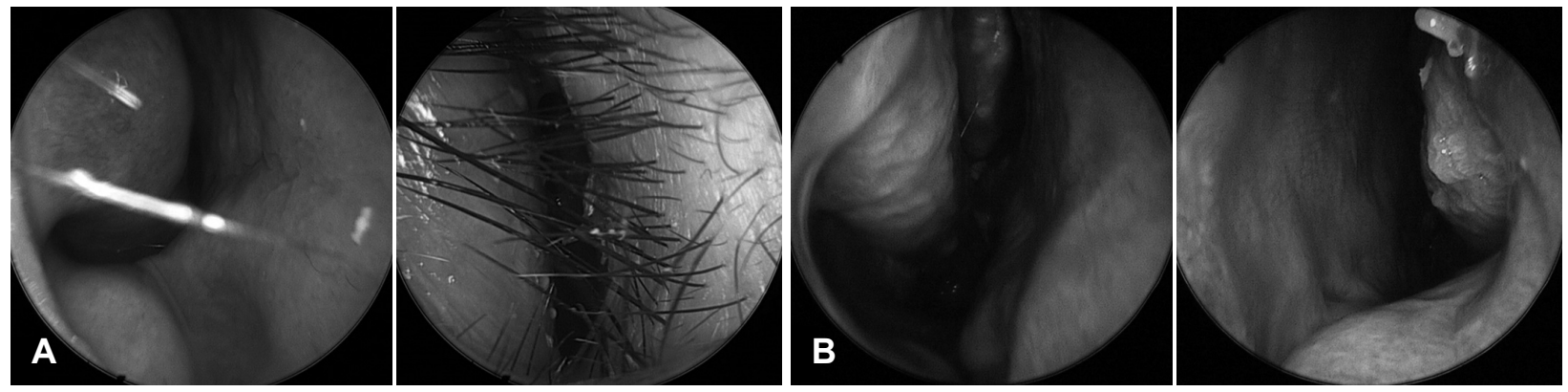

Fig. 1. Preoperative (A) and postoperative (B) endoscopic findings.
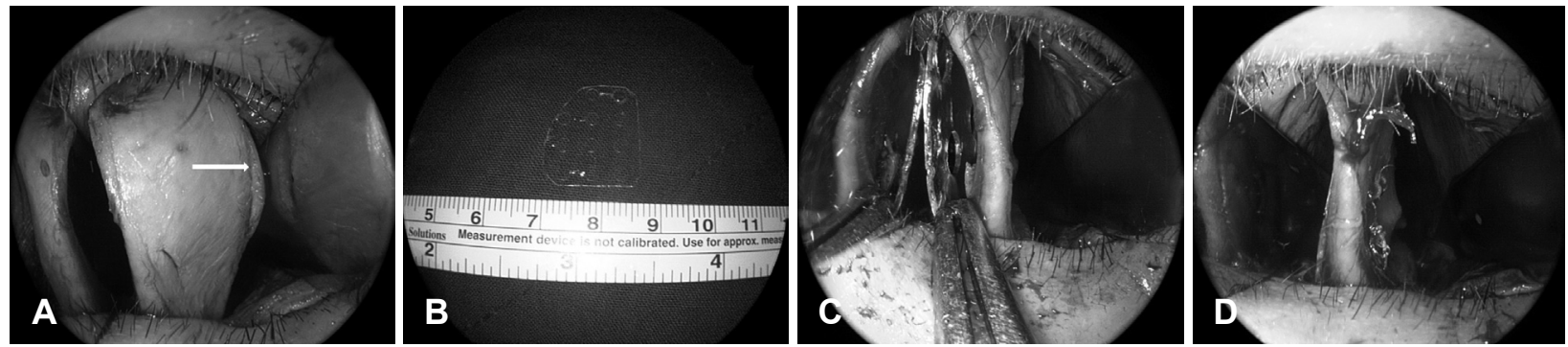

Fig. 2. Surgical procedures of caudal septal batten graft with bioabsorbable plate. The bilateral mucoperiosteal flap of septum was elevated form the caudal aspect of the cartilage. Fracture line in the caudal septal cartilage was seen (arrow) (A). Designed bioabsorbable plate for caudal septal batten graft (B). A caudal septal batten graft was fitted to the desired location (C). The caudal septal batten graft and the caudal nasal septum were closed using the through-and-through suture (D). 
Table 1. Clinical summary of patients with caudal batten graft

\begin{tabular}{|c|c|c|c|c|c|c|c|c|}
\hline Case & $\begin{array}{l}\text { Age, } Y / \\
\text { sex }\end{array}$ & $\begin{array}{l}\text { Primary/ } \\
\text { revision }\end{array}$ & $\begin{array}{l}\text { Deviation } \\
\text { direction }\end{array}$ & Approach & $\begin{array}{l}\text { Additional } \\
\text { procedures }\end{array}$ & $\begin{array}{c}\text { Wound } \\
\text { complications* }\end{array}$ & $\begin{array}{l}\text { External nose } \\
\text { deformities }^{\dagger}\end{array}$ & $\begin{array}{l}\text { Follow-up } \\
\text { (months) }\end{array}$ \\
\hline 1 & $29 / F$ & Primary & Left & Endonasal & Turbinoplasty & None & None & 9 \\
\hline 2 & $27 / M$ & Primary & Right & External & Turbinoplasty & None & None & 7 \\
\hline 3 & $58 / \mathrm{M}$ & Revision & Right & Endonasal & Turbinoplasty & Mucosal defect & None & 9 \\
\hline 4 & $24 / F$ & Primary & Left & Endonasal & Turbinoplasty & None & None & 4 \\
\hline 5 & $42 / F$ & Revision & Right & External & $\begin{array}{l}\text { Augmentation } \\
\text { rhinoplasty, } \\
\text { turbinoplasty }\end{array}$ & None & None & 9 \\
\hline 6 & $23 / M$ & Revision & Right & External & $\begin{array}{l}\text { Augmentation } \\
\text { rhinoplasty, } \\
\text { turbinoplasty }\end{array}$ & None & None & 13 \\
\hline 7 & $23 / M$ & Revision & Left & External & $\begin{array}{l}\text { Humpectomy, } \\
\text { augmentation } \\
\text { rhinoplasty, } \\
\text { turbinoplasty }\end{array}$ & None & None & 13 \\
\hline
\end{tabular}

*wound complications include infection, septal hematoma, septal perforation or mucosal defect, ${ }^{t}$ external nose deformities include saddle deformity, retraction of the columella or loss of tip projection. Y: years, M: male, F: female

\section{임상경과}

2014년 7월부터 2015년 8월까지 7명의 환자가 비중격 미부 만곡증을 교정하기 위해 생체흡수성 판 부목이식을 시행받 았다. 환자 중에 남자가 4명, 여자가 3명이었으며, 평균 연령은 32.2 세, 수술 후 경과 관찰 기간은 최소 4개월부터 최대 13 개 월까지 평균 9.2개월이었다(Table 1). 모든 환자에서 재수술이 필요할 정도의 주요 합병증 및 이식에 따른 수술부위 감염이 나 이물질에 대한 거부반응은 없었으며, 마지막 경과 관찰 시 점까지 비중격 미부의 만곡이 재발한 경우나 외비의 변형이 발생한 경우는 없었다. 한 명의 환자에서 수술 중 점막판이 찢 어진 부위에 점막 결손이 발생하여 생체흡수성 판이 일부 노 출되었는데, 이차 감염은 없었고 수술 후 6개월이 경과된 시점 에서 점막이 완전히 회복되어 결손부위가 사라졌다.

\section{고 찰}

부목이식은 코성형술을 시행하는 과정에 다양한 해부학적 이상을 교정하는 목적으로 사용되는 술식이지만 만곡된 비중 격을 교정하기 위한 부목이식에 대한 적응증은 명확하게 설정 되어있지 않다. 심한 비중격 만곡이라도 골부에 국한되어 있거 나 L형 지주가 포함되지 않는 경우, 또는 L형 지주가 포함되더 라도 연골의 만곡이 심하지 않고 탈구에 의한 변형인 경우는 점막하절제술(submucosal resection), 교차절개, 쐐기절제, 고 정봉합(anchoring suture)과 같은 기존의 고식적 술식으로 충 분히 교정이 가능하다. ${ }^{2,7}$ 하지만 비중격 연골의 두께가 얇고 L 형 지주를 포함한 비중격 연골 미부의 심한 만곡이 동반된 경 우는 기존의 술식으로는 만곡의 교정도 어려울 뿐 아니라, L 형 지주를 보존한다 하더라도 충분한 지지력을 갖지 못해 외
비기형을 유발할 위험성이 높아진다. 이런 경우는 단단한 구 조물의 보강을 통해 L형 지주의 충분한 지지력을 갖도록 하여 외비변형을 예방하면서, 연골의 잔존장력이나 복원력을 차단 하여 회복시 만곡의 재발을 억제하는 효과가 있는 부목이식 을 통한 연골부위의 만곡을 교정하는 것이 효과적인 것으로 알려져 있다. ${ }^{8,9}$

부목이식은 1956년 Dingman ${ }^{10}$ 에 의해 처음으로 소개된 이 후 최근 비중격 미부의 만곡을 교정하는 방법으로서 좋은 임 상결과들이 보고되고 있다.,6) 수술 중에 채취할 수 있는 비중 격 연골이 채취가 쉽고 이식편의 생착률도 좋아 부목이식의 주 재료로 사용되지만, ${ }^{5)}$ 최근에는 사골 수직판이나, 서골 골 편을 이용한 골부목이식(bony batten graft)법이 소개되었고, 연골을 이용한 부목이식과 유사한 임상결과 보이는 것으로 알려졌다. ${ }^{11)}$ 부목이식의 재료로 비중격 연골을 사용한 경우 이식된 연골이 교정된 만곡부위의 지지대로 작용하지만 치유 과정에서 만곡을 유지하려는 비중격 연골의 복원력을 극복할 정도의 강도를 유지할 수 있는지 예측하기 힘들며, ${ }^{12)}$ 이식편의 두께로 인해 이식편이 위치한 부위의 비강 단면적이 감소되어 오히려 비폐색이 심화될 가능성이 있다는 단점도 있다. ${ }^{12}$ 그리 고 무엇보다 과거 점막하절제술을 받았던 재수술이 계획된 환자나 비중격 연골부의 골절이 의심되는 경우, 비중격 연골 부 및 골부의 심한 만곡증이 동반된 경우는 부목이식을 통해 만곡을 교정하기에 충분한 크기와 강도의 곧은 이식편을 확보 하기가 어렵다는 문제점이 있다.

부목이식을 위한 자가조직이 충분하지 못한 경우 합성물질 (alloplastic material)을 사용할 수 있으며, 생체흡수성 폴리머 인 polydioxanone(PDS; Ethicon, Norderstedt, Germany) 판 이 체외비중격재건술(extracorporal septal reconstruction)시 
비중격 연골을 고정하는 뼈대(scaffold)로 많이 사용되고 있 다. ${ }^{13)} \mathrm{PDS}$ 판은 25주 이내에 체내에서 완전히 흡수되기 때문 에 합성물질에 의한 장기적으로 발생할 수 있는 이물반응 (foreign body reaction)에 의한 만성염증이나 2차감염의 위 험성이 낮은 재료로 알려져 있으며, 수술 후 10주까지 생체 내에서 구조적 형태 및 강도가 유지되기 때문에 연골이 재형 성(remodel)되고 주변의 연부조직이 회복되면서 외피를 형성 하여 안정화될 때까지 지지역할을 하는 것으로 알려져 있다. ${ }^{14)}$

본 증례에 사용된 합성물질은 Poly $(\mathrm{D}, \mathrm{L})$-lactic acid로 구성 된 생체흡수성 폴리머(Resorb-X ${ }^{\circledR}$; KLS Martin, Tuttlingen, Germany)로 기계적 강도는 10주까지 유지되면서 30개월 이 내 체내에서 완전히 흡수되어 제거가 필요 없고, 이식부위 골 성장에 영향을 주지 않아 현재 두개안면성형수술(craniofacial plastic surgery)에 많이 사용되는 제품으로 PDS와 유사 한 특성을 보이며, ${ }^{15,16)}$ 비중격 골절 환자의 내부 부목(internal splint)으로 사용이 보고되었던 안정적인 제제이다. ${ }^{17)}$ 현재 국 내에서 PSD 판은 유통되지 않기 때문에 실제 임상에 적용이 어려우며, 비슷한 효과와 안전성이 보고된 $0.3 \mathrm{~mm}$ 두께의 구 멍이 있는(perforated) 형태의 생체흡수성 판을 이용하여 부 목이식을 통한 비중격 미부 교정을 시도하였다. 생체흡수성 판은 다양한 두께와 구멍의 유무에 따라 구멍이 있는 형태와 구멍이 없는(non-perforated) 형태가 있지만, 구멍이 있는 형 태가 부목이식을 시행할 때 봉합을 하기에 수월한 장점도 있 고, 수술 이후 회복기간에 연골은 점막연골막판(mucoperichondrial flap)을 통해 혈류공급을 받기 때문에 구멍이 있는 형태의 생체흡수성 판이 연골의 재생에 더 좋은 것으로 알려 져 있어 구멍이 있는 형태의 생체흡수성 판을 선택하였다. ${ }^{18)}$ 저자들은 7예의 심한 비중격 미부 만곡증이 동반된 환자에 서 생체흡수성 판을 이용하여 부목이식을 시행하였고, 비중 격 만곡부위의 재발, 점막의 괴사, 이식부위의 염증, 외비의 형 태변화와 같은 주요 합병의 발생 없이 만족스러운 수술 결과 를 경험하였다. 장기적 경과 관찰과 수술 효과에 대한 정량적 평가에 대한 추가적인 연구가 필요하겠지만, 자가조직을 충분 히 얻을 수 없는 비중격 미부의 만곡이 심한 환자의 치료에서 생체흡수성 판을 이용한 부목이식법이 새로운 대안이 될 수 있을 것으로 생각한다.

\section{REFERENCES}

1) Jin HR, Won TB. Septoplasty; current concept and technique. J Rhinol 2008;15(1):13-29.

2) Min YG, Chung JW. Cartilaginous incisions in septoplasty. ORL J Otorhinolaryngol Relat Spec 1996;58(1):51-4.

3) Lee BJ, Chung YS, Jang YJ. Overcorrected septum as a complication of septoplasty. Am J Rhinol 2004;18(6):393-6.

4) Wee JH, Lee JE, Cho SW, Jin HR. Septal batten graft to correct cartilaginous deformities in endonasal septoplasty. Arch Otolaryngol Head Neck Surg 2012;138(5):457-61.

5) Kim JH, Kim DY, Jang YJ. Outcomes after endonasal septoplasty using caudal septal batten grafting. Am J Rhinol Allergy 2011;25(4): e166-70.

6) Nakayama T, Okushi T, Yamakawa S, Kuboki A, Haruna S. Endoscopic single-handed septoplasty with batten graft for caudal septum deviation. Auris Nasus Larynx 2014;41(5):441-5.

7) Dhong HJ, Kim HY, Chung MK. Septoplasty with conservative resection and figure of 8 anchoring suture for the caudal septal deviation. Korean J Otolaryngol-Head Neck Surg 2005;48(1):51-5.

8) Metzinger SE, Boyce RG, Rigby PL, Joseph JJ, Anderson JR. Ethmoid bone sandwich grafting for caudal septal defects. Arch Otolaryngol Head Neck Surg 1994;120(10):1121-5.

9) Jang YJ, Yeo NK, Wang JH. Cutting and suture technique of the caudal septal cartilage for the management of caudal septal deviation. Arch Otolaryngol Head Neck Surg 2009;135(12):1256-60.

10) Dingman RO. Correction of nasal deformities due to defects of the septum. Plast Reconstr Surg (1946) 1956;18(4):291-304.

11) Chung YS, Seol JH, Choi JM, Shin DH, Kim YW, Cho JH, et al. How to resolve the caudal septal deviation? Clinical outcomes after septoplasty with bony batten grafting. Laryngoscope 2014;124(8): 1771-6.

12) André RF, Vuyk HD. Reconstruction of dorsal and/or caudal nasal septum deformities with septal battens or by septal replacement: an overview and comparison of techniques. Laryngoscope 2006;116(9): 1668-73.

13) Conderman C, Kinzinger M, Manuel C, Protsenko D, Wong BJ. Mechanical analysis of cartilage graft reinforced with PDS plate. Laryngoscope 2013;123(2):339-43.

14) Boenisch M, Mink A. Clinical and histological results of septoplasty with a resorbable implant. Arch Otolaryngol Head Neck Surg 2000;126(11):1373-7.

15) Heidemann W, Gerlach KL. Sonographic examinations on the degradation of bioresorbable osteosynthesis materials. Biomed Tech 2001;46(S1):48-9.

16) Losken HW, van Aalst JA, Mooney MP, Godfrey VL, Burt T, Teotia $\mathrm{S}$, et al. Biodegradation of Inion fast-absorbing biodegradable plates and screws. J Craniofac Surg 2008;19(3):748-56.

17) Kim JN, Choi HG, Kim SH, Park HJ, Shin DH, Jo DI, et al. The efficacy of bioabsorbable mesh as an internal splint in primary septoplasty. Arch Plast Surg 2012;39(5):561-4.

18) Tweedie DJ, Lo S, Rowe-Jones JM. Reconstruction of the nasal septum using perforated and unperforated polydioxanone foil. Arch Facial Plast Surg 2010;12(2):106-13. 